International Journal of Instruction e-ISSN: 1308-1470 • www.e-iji.net

Article submission code: 20201023062017

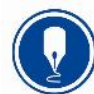

October $2021 \bullet$ Vol.14, No.4

p-ISSN: 1694-609X

pp. 411-426

Received: 23/10/2020

Revision: 20/03/2021
Accepted: 13/04/2021

OnlineFirst: 02/08/2021

\title{
Perception of Instructors' and Their Implementation of Critical Thinking within Their Lectures
}

\section{Jehan A. Alandejani}

Asst. Prof.. Northern Border University, Saudi Arabia, jehanalandejani@nbu.edu.sa, j.andejani@gmail.com

A shared learning outcome for baccalaureate programs is for students to think critically and utilize critical thinking skills. However, education in Saudi Arabia seems to has focused more on rote memorization. Critical Thinking (CT), one of several essential skills regarded in college outcomes, has become a vital citizenry skill in Saudi. In this study, the researcher examined whether or not instructors apply CT or use its components in their teaching. This study offers professional development specialists insight on what to focus on when planning and developing critical thinking workshops. Participants in this study included instructors from a small-sized university in Saudi Arabia. A descriptive analysis, multiple regression, and MANOVA tests were implemented. The results of this study indicated that the majority of instructors use CT within their lectures. Furthermore, the results showed that younger instructors seem more likely to implement CT activities. There was no significant difference between science disciplines and humanities disciplines when implementing $\mathrm{CT}$ in their classes.

Keywords: critical thinking, professional development, cultural theory, learning, lectures

\section{INTRODUCTION}

The method we teach with can be as important as what we teach (Timpson, 2002). It is not an argument that the purpose of higher education is to prepare learners to become active participants in a democratic society (Baumfield, 2006; Erikson \& Erikson, 2018). With technology advancements and rapid change, university instructors face challenges in adjusting their teaching approaches to prepare students for new opportunities and life experiences (Erikson \& Erikson, 2018). Saudi's education system is pushing towards implementing change and developing 21 st-century skills, especially critical thinking (CT), to Saudi's Economic Vision 2030 (Vision, 2030).

$\mathrm{CT}$ is an essential element in university education. It is the ability to actively use higherorder thinking skills that include practicing to skillfully conceptualize, synthesize, and evaluate concepts and ideas to increase understanding and knowledge of reality (Robert \& Charles, 1989; Egege \& Kutieleh, 2004). CT acts as both a liberating force in education and a powerful resource for personal and civil growth (Facione, 1990).

Citation: Alandejani, J. A. (2021). Perception of instructors' and their implementation of critical thinking within their lectures. International Journal of Instruction, 14(4), 411-426. https://doi.org/10.29333/iji.2021.14424a 
Critical thinking skills (CTS) provide students with real-life experiences and simulate real-life situations where students can practice CTS (Robert \& Charles, 1989). Many studies talk about the techniques and strategies that instructors should use to teaching CT, but a few studies talk about the actual knowledge and perceptions university instructors acquire (Alwadai, 2014; Almulla, 2018; Al-Ghamdi \& Deraney, 2013; Zhang $\&$ Zhang, 2013). This study investigates the perception of instructors about CT and their ability to use all CTS components.

\section{Literature Review}

In general, it is difficult to find an education curriculum that does not include CT in its lists of learning outcomes and core pedagogy (Al-Ghamdi \& Deraney, 2013). However, according to Robert \& Charles (1989), students do not learn and implement CTS unless schools teach CT in consecutive terms. Universities insist that CT is an essential outcome, yet many lack the ability to teach CT (Egege \& Kutieleh, 2004).

Early CT research focused on whether instructors understood the concept (Paul, Edler \& Bartell, 1997). According to Egege and Kutieleh (2004), instructors might understand what $\mathrm{CT}$ is but may not clearly understand the concept. Moreover, some studies found a lack of instructional technique by faculty on implementing CT within their teaching. Without the proper techniques, instructors cannot provide students with the tools they need, leaving students with limited cognitive and metacognitive experiences (AlGhamdi \& Deraney, 2013). In the absence of CT skills, students tend to memorize lessons rather than critically inquire (Goodlad, 1984). According to Allamankhrah (2013), rote-learning and memorization are the main methods of instruction in Saudi with which students are dissatisfied. On the other hand, when students engage in CT and evaluate problems in classroom discussions, their CT skills can improve over a 14-week term (Godzella et al., 1996).

Smith \& Stitts (2013) asserted that CT, as an approach, concerns a full process of teaching that consists of different tools and techniques, and instructors need to commit to the process of CT. The authors concluded that instructors need to incorporate engagement into the learning environment and continuously improve the learning process. Zhang \& Zhang (2013) stated that when instructors provide a positive and engaging environment, students use CT more, which results in stronger effects on cognitive engagement.

A previous study that examined instructors' perception of their students' levels of CT found that CT application in the classroom is a complex and developmental process. Instructors viewed student levels of CT as below the expected level for graduate students. Moreover, instructors focused on CT's different concepts, and when instructors were asked how they evaluated CT in their classrooms, they had difficulty answering (Nicholas \& Raider-Roth, 2016). Another study indicated that instructors are good with CT and can implement it well. However, when it comes to assessing CT in classrooms, instructors still face difficulties. Instructors find it hard to connect between their teaching approach and how they evaluate CT (Nicholas \& Labig, 2013). 
Asharaah \& Al-Nabrawi (2012) investigated the difference between Saudi and Jordanian CTS of teachers and the impact of gender and experiences in science qualification. The results showed no significant difference related to gender, but there was a significant difference related to scientific qualification. Thus, there is a need to understand instructors' perception of CT in different disciplines to develop aimed instruction for teaching directed CTS (Alwehaibi, 2012).

Saudi universities have only recently begun implementing CT, personal development, and leadership courses (AlWehaibi, 2011; Al-Ghamdi \& Deraney, 2013) into higher education curricula. However, there seems to be a lack of knowledge in CT's definitions and its relation to problem-solving in Saudi Arabia. In the last decade, researchers question Saudi educational institutions and the lack of focus on CTS use (Al-Ghamdi \& Deraney, 2013). According to Gashan (2015), studies should explore CT knowledge among college instructors.

Teacher training and developing CTS strategies are essential to reach Saudi's Economic Vision 2030 (Allmnakrah, 2019). Therefore, professional development and training are necessary for staff members to improve themselves in the areas in which they are specialized (Tseng, 2006). The goal is to train participants to master the knowledge, skills, and behaviors emphasized in the training programs and apply them to their dayto-day activities (Noe, 2002). When instructors take professional development in thinking skill approaches, it helps them become more aware of the topic and how to implement them into their lectures (Erikson \& Erikson, 2018).

Saudi scholars have been asked to incorporate CT in education programs in the last decade to elevate the quality of teaching in Saudi Arabia (Ashraah et al., 2010; Allamnakhrah, 2013). Consequently, it is essential to examine instructors' perceptions of CT (Alwehaibi, 2012). This study investigates whether instructors at Saudi universities use CT or use some CT components in their teaching. Keeping in mind that CT has been embedded in the last decade and was not thoroughly integrated into teaching (Ashraah et al., 2010).

The cultural theory informs the study that states, individuals are culturally pre-coded according to their "origin and basic structure of which the individual has already prepared" (Ziehe, 2009, p. 185). They are carried out by biographical pre-impressions and norms of what their general culture has directed them. Individuals build their underlying convictions through cultural knowledge that is reflected through their actions. The cultural theory will help examine the perception of instructors at Saudi universities about CT. It will also investigate the difference in the use of CT components between science disciplines and human disciplines. The differences in CT implementation for the university instructors will be assessed with the following hypotheses:

Hypothesis 1: Instructors teaching in science disciplines use CT components more than instructors teaching in human science disciplines.

Hypothesis 2: Instructors use only some components of CT. 


\section{METHOD}

\section{Participants}

Participants of this study included instructors from a small-sized university in Saudi Arabia. The participants were anonymous. Snowball sampling was used where the researcher asked participants to identify other potential participants to become part of the study. At the time of the study, the number of faculty members in both science and human science disciplines was about 1,300. Data from 112 instructors (49 females, 63 males) were gathered. The majority of the group (67\%) were assistant professors. Also, most of the group (77\%) were faculty between thirty to forty-five years. Approximately (66\%) of the instructors were from Science disciplines, and (46\%) were from Humanity disciplines. The "Position" variable is used and had four levels depending on the university's setting: lecturer, assistant professor, associate professor, and professor. The participants' nationality and years of experience were collected and varied, as shown in Table 1.

Table 1

Participants demographics

\begin{tabular}{lll}
\hline Characteristics & $n$ & $\%$ \\
\hline Nationality & & \\
\hline Saudi & 29 & 25.57 \\
\hline Egyptian & 32 & 28.56 \\
\hline Tunisian & 15 & 13.39 \\
\hline Sudanese & 1 & .89 \\
\hline Jordanian & 5 & 4.46 \\
\hline Missing & 18 & \\
\hline Years of Experience & & 30.36 \\
\hline 1 to 5 years & 34 & 22.32 \\
\hline 6 to 10 years & 25 & 13.39 \\
\hline 11 to 15 years & 15 & 21.43 \\
\hline 16 to 20 years & 24 & 12.50 \\
\hline More than 21 years & 14 & \\
\hline
\end{tabular}

\section{Instruments}

A survey was used to measure individual attitudes towards CT and how CT is used in their lectures. The questionnaire was created using Google ${ }^{\circledR}$ Forms. The survey consists of the main five components of CT: information collection, organization, application, analysis, and synthesis (Facione \& Gittens, 2011; Zhang \& Zhang, 2013). The survey aims to measure the instructor's use of CT activities for students. The instrument was adapted from two main popular tests; the Critical Thinking Assessment Test (CAT) and the Foundation for Critical Thinking (2018). The survey was divided into two parts. The first part covered demographics, and the second included CT-related questions based on a 5-point Likert scale. The Likert Scale contained five sections, and each section asked about one of the main components of CT: information collection, organization, application, analysis, and synthesis (Facione \& Gittens, 2011; Zhang \& Zhang, 2013). The participants were asked to respond on a 5 -point scale $(1=$ never, $5=$ 
always). The reliability of each element of CT was validated using Cronbach's alpha test.

\section{Information collection}

Information from 112 participants was collected and measured using the 12-question survey. The questions focused on three areas: how instructors provided students with information, what method of instruction they used, and how they motivated students to collect data from various reliable sources. The Cronbach's alpha was 0.94 , which provided excellent support for the internal consistency of reliability (Morgan et al., 2011).

\section{Organizing Information}

The organizing information component was categorized under four questions in the survey to learn how instructors motivated students to organize information and how instructors typically help students differentiate between the kind of information based on what is right and what can be true. The Cronbach's alpha was 0.88 , which provided good support for the internal consistency of reliability (Morgan et al., 2011).

\section{Analysis and Synthesis}

The analysis and synthesis component was divided into six questions in the survey. The questions asked if instructors help students make connections between varying information and motivate them to make appropriate generalizations. Cronbach's alpha was 0.86 , which provided good support for the internal consistency of reliability (Morgan et al., 2011).

\section{Application}

The application component was measured by asking four questions in the survey. The questions asked if instructors help students compare different ideas and recognize the various effects of different assumptions and theories. Cronbach's alpha was 0.90 and provided good support for the internal consistency of reliability (Morgan et al., 2011).

\section{Procedure}

Since instructors varied between bring English speaking or Arabic speaking and to maximize the validity of the study, the questionnaire was developed in English and then translated into Arabic to provide conceptual equivalence and context. The questionnaire was created using Google (B Forms for quick dissemination and response. Participants received the questionnaire through email by a link and the social media application, WhatsApp. The electronic questionnaire required about 15 minutes to complete and consisted of personal, attitudinal, and behavioral questions. The participants were anonymous. The researcher chose snowball sampling, asking current participants to identify potential participants for the study. Snowball sampling helped maintain participant anonymity and eliminate the researcher's possibility of knowing or identifying participants who did not return the study (Morgan et al., 2011). 
The participants were not randomized, first come, first serve. Therefore, the group's equivalent internal validity would be ranked as medium (Gignac \& Szodorai, 2016). On the other hand, there were no attempts to control the experience and the environment of the variables except that all participants were from the same university. Again, internal validity for environment variables would be ranked medium, according to Cohen's (1988) guidelines (Gignac \& Szodorai, 2016).

\section{FINDINGS}

To assess the survey results and test if and how the five components of CT are being used in the university curriculum courses, descriptive, MANOVA, and multiple regression tests were implemented. All statistical analyses were completed using Minitab18 ${ }^{\circledR}$ software and at a confidence level of $95 \%$, with $\alpha=0.05$.

\section{Descriptive Analysis}

Data from 112 instructors (49 females, 63 males) were gathered. Table 2 presents the means, standard deviation, and skewness of the ordinal and key variables. Four variables represent CT components: Information Collection, Organization, Analysis and Synthesis, and Application. The variable "Critical Thinking" represents overall CT, which is calculated based on the CT components' means from each participant. Table 2 also shows that on a scale of 1-5, CT components and overall CT are approximately 4, suggesting that instructors use CT. The means correspond to the level "agree," since most of the instructors stated that they use all components of CT.

Table 2

Descriptive statistics for variables

\begin{tabular}{lllll}
\hline & $\mathrm{N}$ & Mean & Std. Deviation & Skewness \\
\hline Gender & 112 & 1.56 & 0.49 & -.26 \\
\hline Age & 112 & 2.26 & 0.51 & 0.64 \\
\hline College & 112 & 1.58 & 0.49 & -0.37 \\
\hline Position & 112 & 1.86 & 0.70 & 0.83 \\
\hline Information Collection & 122 & 4.04 & 0.72 & -0.82 \\
\hline Organization & 122 & 4.00 & 0.86 & -0.86 \\
\hline Analysis \& Synthesis & 122 & 4.11 & 0.73 & -1.04 \\
\hline Application & 122 & 4.10 & 0.85 & -1.28 \\
\hline Critical Thinking & 112 & 4.32 & 0.81 & -1.08 \\
\hline
\end{tabular}

Also, with the exceptions of Age and Position, the outcomes of most of the variables were negatively skewed. All skewness ranged between -1 and +1 . Except for "Application," which had a skewness of -1.28 , the data was assumed to be approximately normal (Morgan et al., 2011).

As mentioned earlier, the four components of $\mathrm{CT}$ were also grouped into one variable called "CT." Further analysis of the data was completed for the overall "Critical Thinking" variable to investigate the participants' responses and highlight any differences due to the demographic variables. Figure 1 shows the normality curve for $\mathrm{CT}$ and indicates that the CT variable was approximately normal in distribution and slightly left-skewed. The figure provides more evidence that, for the most part, 
instructors stated that they use CT in their lectures. Thus, the second hypothesis, which states that instructors use some components of CT, would be rejected. On average, it appears that instructors believe that they use all components of CT since the means of the four individual CT components correspond to the response "agree."

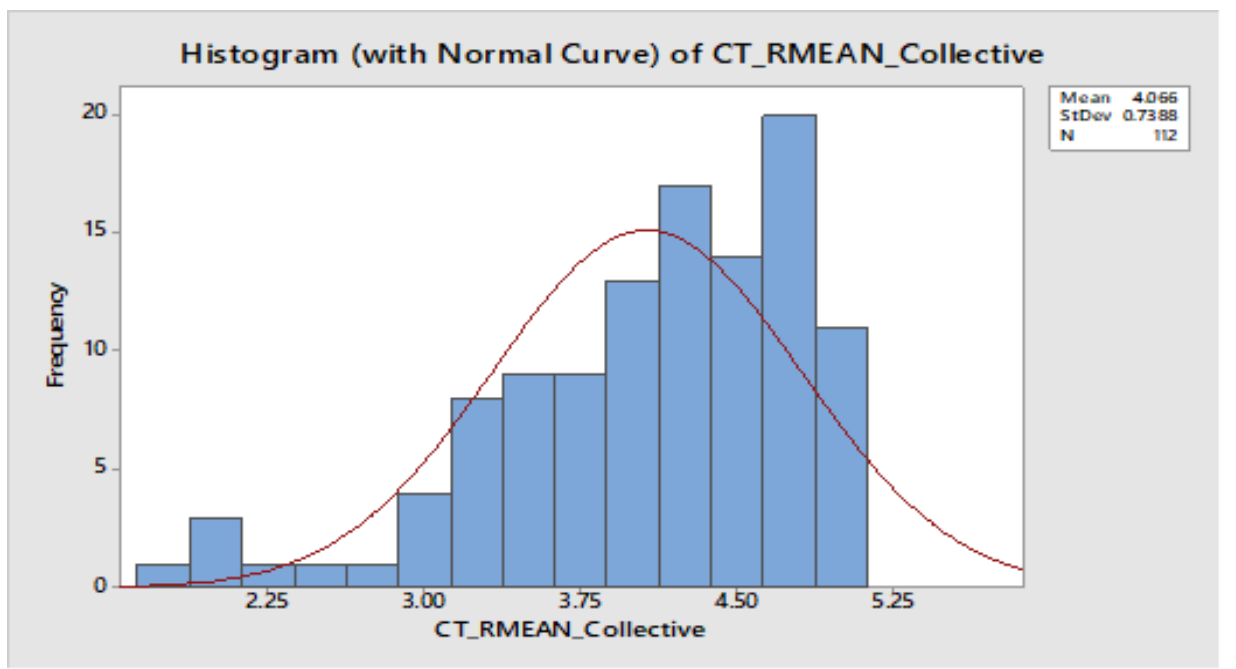

Figure 1

Normality curve for CT

The contribution of each component of CT used by instructors to the overall critical thinking is presented in table 3 . "N" denotes the number of participants recording the corresponding response (never to always), and "Mean" represents the means of each response level. The table indicates that very few instructors never or rarely use components of CT. On the other hand, the table shows that most instructors believe that they are most likely or always use components of CT. Finally, a decent number of instructors varying from 12 to 22 instructors out of the total 112 participants recorded the response "neutral," indicating that they either do not use CT components or that they are not familiar with these components. The results shown in table 3 validates the descriptive analysis for the CT components indicated in Table 2 earlier.

Table 3

The frequency of the CT components

\begin{tabular}{|c|c|c|c|c|c|c|c|c|c|c|}
\hline \multicolumn{11}{|c|}{ CT Components } \\
\hline \multirow{2}{*}{ Response } & \multicolumn{2}{|c|}{ InfoCo } & \multicolumn{2}{|c|}{ Org } & \multicolumn{2}{|c|}{ Anay } & \multicolumn{2}{|c|}{ App } & \multicolumn{2}{|c|}{ HW } \\
\hline & $\mathrm{N}$ & Mean & $\mathrm{N}$ & Mean & $\mathrm{N}$ & Mean & $\mathrm{N}$ & Mean & $\mathrm{N}$ & Mean \\
\hline Never & 0 & NA & 0 & NA & 0 & NA & 3 & 1.8361 & 0 & NA \\
\hline Rarely & 3 & 1.868 & 8 & 2.335 & 8 & 2.335 & 2 & 2.150 & 9 & 2.601 \\
\hline Natural & 22 & 3.1907 & 15 & 3.3588 & 15 & 3.3588 & 12 & 3.1794 & 17 & 3.569 \\
\hline Most Likely & 47 & 4.067 & 40 & 3.9504 & 40 & 3.9504 & 46 & 3.8962 & 44 & 4.0105 \\
\hline Always & 40 & 4.712 & 49 & 4.6603 & 49 & 4.6603 & 49 & 4.6581 & 42 & 4.6404 \\
\hline
\end{tabular}




\section{Regression Analysis}

Due to the number of dependent and independent variables and the normality of the data, extended statistical analyses were completed. The goal was to assess further the impact of the independent variables on the level of CT being implemented in class in relation to the instructors' characteristics. Multiple regression analysis can be used for several reasons. It can investigate the best predictors of CT scores to identify statistically significant independent variables and their corresponding coefficients. It can also allow the researcher to consider the best combination of independent variables that predict the dependent variable. The robustness of multiple regression analysis makes it a suitable method for the two hypotheses considered.

Specifically, multiple regression was used in this research to test the relationship between CT as a dependent variable and the independent variables "Age," "Gender," "College," and "Position." The procedure started with considering all independent variables followed by a run of the regression. The process was then repeated, considering only the independent variables that affected the regression most. The implementation of multiple regression in such a way can help resolve Hypothesis 1 that states: Instructors teaching in science disciplines use CT components more than instructors teaching in human science disciplines.

An Analysis of Variance was used to determine statistically significant differences if any. Table 4 below shows the ANOVA results for the regression model that considered all independent variables. The regression analysis seems to be statistically insignificant $(p>0.05)$. Based on the results, the only significant independent variable from this model is "Age" $(p<0.05)$. All other independent variables appear to be statistically insignificant $(\mathrm{p}>0.05)$. The most insignificant variables are" College," with F-value $=0.08$ and $\mathrm{p}=$ 0.782, and" Experience," with F-value $=0.092$ and $p=0.339$. Regression coefficients are shown in Table 5 to show the relationship between variables. The statistically significant coefficients are the coefficient of the constant term, the coefficient of "Age," and the coefficient of the level "Lecturer" within the independent variable "Position." All other independent variable coefficients are statistically insignificant $(p>0.05)$. The independent variables "Gender" and "College" had regression coefficients equal for both levels of these variables. No difference was observed for the levels of these independent variables. As a result, it seems logical to omit the statistically insignificant independent variables for a better-fit regression model.

Table 4

Analysis of variance of the regression model regarding all independent variables

\begin{tabular}{llllll}
\hline Sources & DF & Adj. SS & Adj. MS & F-Value & P-Value \\
\hline Regression & 7 & 6.6196 & 0.94565 & 1.82 & 0.091 \\
\hline Age & 1 & 3.1155 & 3.11547 & 6.00 & 0.016 \\
\hline Experience & 1 & 0.4794 & 0.47941 & 0.92 & 0.339 \\
\hline Position & 3 & 3.3807 & 1.12690 & 2.17 & 0.096 \\
\hline Gender & 1 & 0.5610 & 0.56095 & 1.08 & 0.301 \\
\hline College & 1 & 0.0400 & 0.03997 & 0.08 & 0.782 \\
\hline
\end{tabular}


Table 5

Coefficients of the regression model

\begin{tabular}{lllll}
\hline Term & Coef. & SE Coef. & T-Value & P-Value \\
\hline Constant & 5.022 & 0.371 & 13.53 & 0.000 \\
\hline Age & -0.381 & 0.155 & -2.45 & 0.016 \\
\hline Experience & 0.0524 & 0.0546 & 0.96 & 0.339 \\
\hline Position & & & & \\
\hline Lecturer & -0.380 & 0.159 & -2.39 & 0.019 \\
\hline Assist Prof & -0.235 & 0.133 & -1.77 & 0.080 \\
\hline Assoc. Prof & 0.103 & 0.207 & 0.50 & 0.621 \\
\hline Prof. & 0.512 & 0.289 & 1.77 & 0.080 \\
\hline Gender & & & & \\
\hline Female & 0.0895 & 0.0860 & 1.04 & 0.301 \\
\hline Male & -0.0895 & 0.0860 & -1.04 & 0.301 \\
\hline College & & & & \\
\hline Humanities & -0.0235 & 0.0848 & -0.28 & 0.782 \\
\hline Science & 0.0235 & 0.0848 & 0.28 & 0.782 \\
\hline A & & & & \\
\hline
\end{tabular}

A second regression model was used to further assess the results and observe the outcomes of omitting the insignificant variables previously indicated. Thus, the regression model was used to predict the dependent variable "Critical Thinking" by considering the independent variables "Age," "Position," and "Gender." This regression model was chosen based on the first regression model's results, omitting the most statistically insignificant independent variables, "Experience" and "College." Table 7 offers the ANOVA results for this regression model, and Table 7 displays the results of the regression coefficients.

Table 6

Level of CT with independent variables (ANOVA results of the second regression model)

\begin{tabular}{llllll}
\hline Source & DF & Adj SS & Adj MS & F-Value & P-Value \\
\hline Regression & 5 & 6.1022 & 1.2204 & 2.37 & 0.044 \\
\hline Age & 1 & 3.0779 & 3.0779 & 5.99 & 0.016 \\
\hline Position & 3 & 3.9820 & 1.3273 & 2.58 & 0.057 \\
\hline
\end{tabular}

Table 7

Level of CT with independent variables (Regression coefficients of the second model)

\begin{tabular}{lllll}
\hline Term & Coef & SE Coef & T-Value & P-Value \\
\hline Constant & 5.085 & 0.355 & 14.32 & 0.000 \\
\hline Age & -0.343 & 0.140 & -2.45 & 0.016 \\
\hline Position & & & & \\
\hline Lecturer & -0.410 & 0.155 & -2.65 & 0.009 \\
\hline Assist. Prof & -0.240 & 0.131 & -1.83 & 0.070 \\
\hline Assoc. Prof & 0.118 & 0.206 & 0.57 & 0.569 \\
\hline Prof. & 0.533 & 0.285 & 1.87 & 0.064 \\
\hline Gender & & & & 0.339 \\
\hline Female & 0.0683 & 0.0710 & 0.96 & 0.339 \\
\hline Male & -0.0683 & 0.0710 & -0.96 & 1 .
\end{tabular}

In the second regression model, i.e., the model that predicted the level of CT implementation based on the independent variables "Age," "Position," and "Gender", 
shows that better statistical results were obtained. The ANOVA analysis provided in Table 6 indicates that the regression model is statistically significant (p-value $<0.05)$. As for the dependent variables, the variable "Age" is still statistically significant, the Variable "Position" is almost statistically significant ( $p=0.057)$, and the variable "Gender" was still statistically insignificant.

The regression coefficients for the second model are shown in Table 7. The table indicates that the constant term of the regression model is statistically significant, and the coefficient of the dependent variable "Age." Moreover, the value of the "Age" coefficient is negative. On the other hand, the coefficients of the different levels of the dependent variable "Position" change from being statistically significant for "Lecturer" $(p<0.05)$ to statistically insignificant for "Associate Professor" $(p>0.05)$. It can also be noted that the values of the coefficients change, being either positive or negative. The coefficients of "Lecturer" and "Assistant Professor" were negative at -0.41 and -0.24 , respectively, whereas the coefficients of "Associate Professor" and "Professor" were positive at 0.118 and 0.533 , respectively. Lastly, the coefficients of both levels of the dependent variable gender are precisely the same and statistically insignificant. Thus, the first hypothesis indicating that instructors in science disciplines use CT more than those in humanities disciplines can be rejected.

At this stage, it seems logical to further optimize the regression model by omitting the statistically insignificant dependent variables, in this case, eliminating "Gender." Table 8 shows the ANOVA results for such a model, and Table 9 shows the regression coefficients. No improvement was obtained in the model or the regression coefficients. Therefore, the author believes that the second model is a better fit in predicting CT since omitting too many variables can have undesired results (Creswell, 2005).

Table 8

Analysis of variance eliminating gender variable

\begin{tabular}{llllll}
\hline Source & DF & Adj SS & Adj MS & F-Value & P-Value \\
\hline Regression & 4 & 5.627 & 1.4068 & 2.74 & 0.032 \\
\hline Age & 1 & 3.591 & 3.5915 & 6.99 & 0.009 \\
\hline Recoded Position & 3 & 3.708 & 1.2361 & 2.41 & 0.071 \\
\hline Error & 107 & 54.964 & 0.5137 & & \\
\hline Lack-of-Fit & 5 & 3.046 & 0.6092 & 1.20 & 0.316 \\
\hline Pure Error & 102 & 51.918 & 0.5090 & & \\
\hline Total & 111 & 60.591 & & & \\
\hline
\end{tabular}

Table 9

Regression coefficients eliminating gender variable

\begin{tabular}{lllll}
\hline Term & Coef & SE Coef & T-Value & P-Value \\
\hline Constant & 5.119 & 0.353 & 14.50 & 0.000 \\
\hline Age & -0.366 & 0.138 & -2.64 & 0.009 \\
\hline Position & & & & \\
\hline Lecturer & -0.390 & 0.153 & -2.54 & 0.012 \\
\hline Assist Prof & -0.236 & 0.131 & -1.80 & 0.075 \\
\hline Assoc. Prof & 0.133 & 0.205 & 0.65 & 0.517 \\
\hline Prof. & 0.492 & 0.282 & 1.75 & 0.084 \\
\hline
\end{tabular}


The Multivariate analysis of variance (MANOVA) can be applied to further assess the significance of the type of college on the prediction of CT. Previous regression results indicated that there was no significant difference in CT application between humanity and science disciplines. MANOVA was conducted to study this hypothesis further. The test considered comparing the effect of the study variables and whether the variable "College" has a significant effect on CT. To test the first hypothesis, MANOVA was conducted for the variable "College" and the interactions with the other variables, namely, "Gender, Age, Position, and Experience". Figure 2 shows data plots for the test; it is clear that all assumptions required for the test are met; hence, MANOVA results are acceptable.

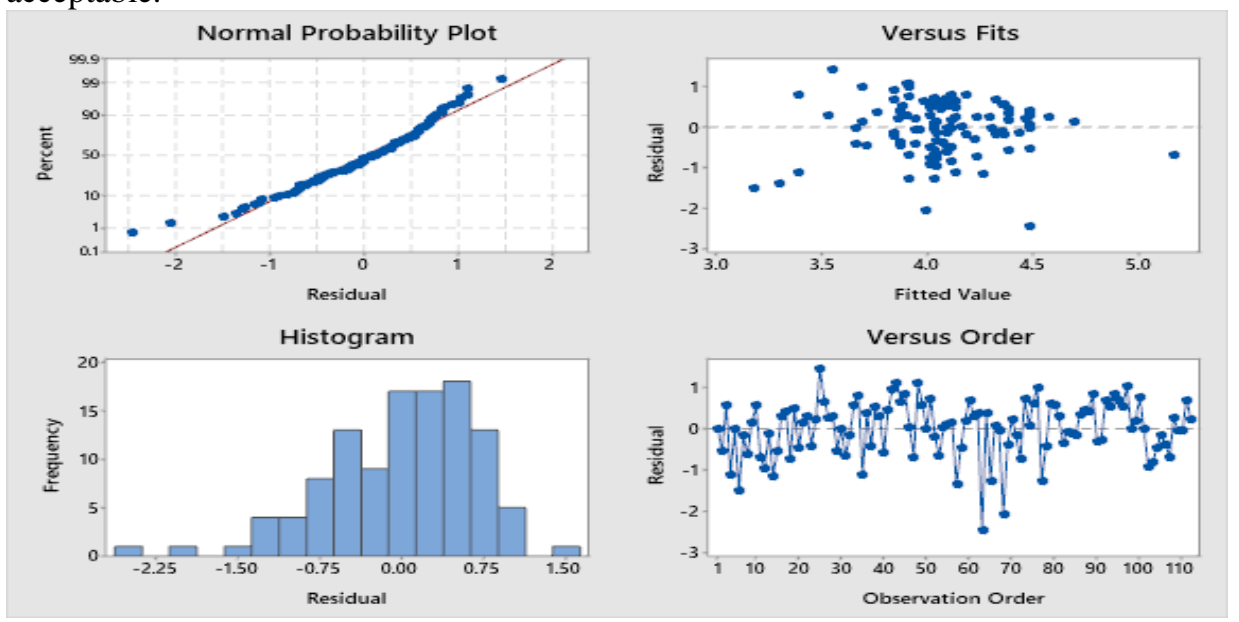

Figure 2

Residual plots for CT

Table 10

MANOVA results for testing the effect of "College" type on the results

\begin{tabular}{llll}
\hline & Wilk's Criterion & & \\
\hline Variable(s) & Test Statistic & F - value & p-value \\
\hline Gender & 0.99052 & 0.977 & 0.325 \\
\hline Age & 0.93239 & 7.396 & 0.008 \\
\hline College & 0.99532 & 0.480 & 0.490 \\
\hline Position & 0.99709 & 0.298 & 0.586 \\
\hline Experience & 0.97888 & 2.200 & 0.141 \\
\hline College*Gender & 0.98507 & 1.546 & 0.217 \\
\hline College*Age & 0.95975 & 4.278 & 0.041 \\
\hline College*Position & 0.99993 & 0.008 & 0.931 \\
\hline College*Experience & 0.98242 & 1.826 & 0.180 \\
\hline
\end{tabular}

Table 10 represents the results of MANOVA for the indicated test. Both LawleyHotelling and Pillai's criteria had the same p-values for all main variables and interactions mentioned in table 10. The only significant variables are "Age" and the interaction "Age*College" at the confidence level of $95 \%$. As indicated in table 10 , the 
differences between the means of all remaining variables and interactions are statistically insignificant. These results further agree with the regression model results where the "College" variable was found insignificant and was omitted from the analysis. It seems that the use of CT depends greatly on the age of the instructors since MANOVA results indicated its significance as well as its interaction with "College". The current analysis and the previous regression analysis clearly showed that no significant difference was observed in CT among humanity and science disciplines; hence, more grounds for rejecting the corresponding hypothesis.

\section{DISCUSSION}

The study aims to examine the perception of instructors at Saudi universities about CT. Two hypotheses were considered in this research. The first states that instructors teaching in Science disciplines use CT more than instructors teaching in Human Science disciplines, and the second speculates that instructors use only some components of CT. The second hypothesis was tested in the descriptive analysis. No further tests were conducted to test the second hypothesis since the means of the five components of CT and the mean of the overall CT were all similar, corresponding to the response "agree." Based on the descriptive analysis, instructors believe that they know and use all five components of CT. This result may be an indication that instructors do know and use all elements of CT, or they think that they do (Egege \& Kutieleh, 2004), and answered the questions of the survey accordingly. The 12-item survey instrument used in the study measured faculty members' beliefs and assessment of their CT applications.

Perhaps, instructors use CT within their lectures. However, they might not be fully committed to the process. Smith and Stitts (2013) noted that CT is an approach that consists of using different tools and techniques. When students do not use CT effectively, they tend to memorize the lessons instead of using inquiry-based learning (Googlag, 1984; Al-Ghamdi \& Deraney, 2013). Therefore, the instructors might not be fully aware of what CT is and how to implement it in their lectures.

The prediction of the use of CT based on the second regression model will be elaborated. The ANOVA represented in Table 5 indicates that "Age" and "Position" are the two main statistically significant variables. Some variations in the results can be outlined from the regression coefficients. The value of the regression coefficients indicates that younger instructors seem to implement CT more than older instructors since the "Age" coefficient was negative and had a higher impact on the overall CT.

On the other hand, the dependent variable "Position" may indicate that lecturers use CT less than assistant professors, associate professors, or professors (least negative and statistically significant coefficient). Simultaneously, it appears that "Professors" use CT more than any different position (highest positive coefficient but insignificant coefficient). Such results indicate that lecturers do not know or do not use CT components and that professors believe that they know and use the components of CT. The differences among the coefficients of regression of the various levels of "Position" was interesting. The insignificance of the regression coefficient of "Associate Professor" might indicate no differences between faculty members across the entire population for this specific level of the position. 
Finally, "Gender", although statistically insignificant, there is an effect of gender on CT. A positive coefficient sign for female instructors and a negative for males indicates that female instructors use CT more than male instructors.

In general, the prediction of CT based on the second regression model indicates that the older the instructor, the less the value of CT since "Age" is the only statistically significant factor in the model. This prediction supports the earlier claim that professors know and use CT components, but they probably do not know that they are fully implementing.

From the findings, we can conclude that instructors rely on their learning style when teaching or the same teaching style in which they were trained. Although instructors might be using some parts of CT, they are likely not familiar with all components of CT. The findings also show that by human nature, individuals are affected by the cultural theory. In other words, participants are culturally pre-coded according to what they have been exposed to or are used to (Ziehe, 2009). Individuals build their underlying convictions through cultural knowledge that is reflected through their actions.

Only in the past decade has higher education shifted in preparing students to be active participants and practice CTS (Ashraah et al., 2010; Allamnakhrah, 2013). Teacher training and the development of CTS strategies are essential to reach Saudi's Economic Vision 2030 (Allmnakrah, 2019). Therefore, when training instructors for CT workshops, workshop facilitators should explain what $\mathrm{CT}$ is and how it can be used in different contexts, and how it can be used within diverse subjects. Instructors need to be taught the accurate meaning of CT and given examples and ideas of implementing all components of CT (Allamankhrah, 2013; Godzella et al., 1996). Also, facilitators of workshops should consider explaining the different components of CT and how to assess them. Workshop facilitators might find resistance from participants to listen inventively and endure CT's true meaning since instructors think that they are already using CT in their teaching. Additionally, professional development workshops could focus more on older faculty members acquainted with the lecturing method.

\section{CONCLUSION}

According to the results of this study, most instructors believe that they use CT within their lectures. This could indicate that instructors believe that they have a good understanding of what CT components are. The results also indicated that younger instructors seem to implement CT more than older instructors. The results revealed that lecturers use CT less than all other faculty or instructor positions. This may be because of their less experience in teaching. Additionally, the study results show that there is no difference between instructors in science disciplines and humanities disciplines. Therefore, the first hypothesis indicating that instructors in science disciplines use CT more than those in humanities disciplines was rejected.

Saudi Arabia is one of the countries working to improve the educational system by moving towards more effective teaching in the 21 st-century, especially CT, to build Saudi's Vision 2030. The study took place in Saudi Arabia. However, the study 
addresses a problem many developing countries face. The findings of this study speak to all developing countries.

Future studies might address more than one university; quantitative research using paired sample faculty-student will help assess both faculty application and students' use of CT. Moreover, a more in-depth study might consider several universities and assess participants' attitudes, use, and CT application through qualitative research.

\section{LIMITATIONS}

One limitation pertains to this study. The survey was written in English, translated into Arabic, and distributed to the instructors. Most Science disciplines use English as the teaching language, while all Humanity disciplines use the Arabic language in teaching. There is a chance this method led to misunderstanding the survey questions or made the participants aware of the purpose of the survey and thus answered the questions in a manner that would indicate the knowledge of the components of critical thinking.

\section{ACKNOWLEDGEMENTS}

The author acknowledges the funding of the Deanship of Scientific Research at Northern Border University, according to the research grant no. COM-2017-1-8-F-7419.

\section{REFERENCES}

Al-Ghamdi, A. H., \& Deraney, P. M. (2013). Effect of Teaching Critical Thinking to Saudi Female University Students Using a Stand-alone Course. International Education Studies, 6(7), 176-188.

Allmnakrah, A., \& Evers, C. (2020). The need for a fundamental shift in the Saudi education system: Implementing the Saudi Arabian economic vision 2030. Research in Education, 106(1), 22-40. https://doi.org/10.1177/0034523719851534

Allamnakhrah, A. (2013). Learning Critical Thinking in Saudi Arabia: Student Perceptions of Secondary Pre-Service Teacher Education Programs. Journal of Education and learning, 2(1), 197-210.

Almulla, M. (2018). Investigating Teachers' Perceptions of their Own Practices to Improve Students' Critical Thinking in Secondary Schools in Saudi Arabia. International Journal of Cognitive Research in Science, Engineering and Education, 6(3), 15-27. DOI: $10.5937 / \mathrm{ijcrsee} 1803015 \mathrm{~A}$

Ashraah, M. M., AL-Nabrawi, I. M., Shdeifat, S., \& Falah al Ali, T. M. (2012). Critical Thinking Skills for Islamic Education Teachers: A Study of Teachers' Perception. International Journal of Academic Research, 4(6), 70-74. DOI: 10.7813/20754124.2012/4-6/B.11

Alwadai, M. A. (2014). Islamic Teachers' Perceptions of Improving Critical Thinking Skills in Saudi Arabian Elementary Schools. Journal of Education and Learning, 3(4), $37-48$. 
Alwehaibi, H. U. (2012). Novel program to promote critical thinking among higher education students: Empirical study from Saudi Arabia. Asian Social Science, 8(11), 193-204.

AlWehaibi, K. (2011, July). The Effect of ACT Program on Developing College Students' CT Skills. Proceeding of the 3RD international conference on education and new learning technologies, Barcelona, Spain.

Baumfield, V. (2006). Tools for pedagogical inquiry: the impact of teaching skills on teachers. Oxford Review of Education, 32(2), 185-196.

Creswell, J.W. (2005). Educational research planning, conducting, and evaluating quantitative and qualitative research. Upper Saddle River, NJ: Person.

Critical Thinking Assessment test. (2018). Retrieved from https://www.tntech.edu/cat/

Erikson, M. G., \& Erikson, M. (2018). Learning outcomes and critical thinking - good intentions in conflict. Studies in Higher Education, 10, 1-11.

Facione, P. A. (1990). Critical Thinking: A Statement of Expert Consensus for Purpose of Educational Assessment and Instruction. Millbrae, CA: California Academic Press.

Facione, P. A. (2015). Critical Thinking: What it is Why it Counts. Millbrae, CA: California Academic Press. Retrieved from https://www.student.uwa.edu.au/_data/assets/pdf_file/0003/1922502/Critical-ThinkingWhat-it-is-and-why-it-counts.pdf

Facione, P. A., \& Gittens, C. A. (2015). Think Critically. Upper Saddle River, NJ: Pearson.

Gashan, A. K. (2015). Exploring Saudi pre-service teachers' knowledge of critical thinking skills and their teaching perceptions. International Journal of Education and Literacy Studies, 3(1), 26-33.

Gignac, G. E., \& Szodorai, E. T. (2016). Effect size guidelines for individual differences researchers. Personality and Individual Differences, 102, 74-78.

Godzella B.M, Gither D.W. \& Bryant G.W, "Teaching and Learning critical thinking skills", Int Congress Psycho., 1996, ED 405313.

Goodlad, J. (1984). A place called school: Prospects for the future. New York, NY: McGraw-Hill.

Hayes, K. D., \& Devitt, A. A. (2008). Classroom Discussions with Student-Led Feedback: A Useful Activity to Enhance Development of Critical Thinking Skills. Food Science Education Research, 7, 65-68.

Howe, R. W., \& Warren, C. R. (1989). Teaching Critical Thinking through Environmental Education. Environmental Education Digest, 2, 1-13.

Landrum, R. E. \& McCarthy, M. A. (2015). Measuring Critical Thinking Skills. In Rajiv S. Jhangiani, Jordan D. Troisi, Bethany Fleck, Angela M. Legg, \& Heather D. 
Hussey (Eds.), A Compendium of Scales for Use in the Scholarship of Teaching and Learning, ( p. $\quad$ 74-86). Retrieved from https://teachpsych.org/Resources/Documents/ebooks/compscalesstl.pdf

Morgan, G. A., Leech, N. L., Gloeckner, G.W. \& Barrett. K. C. (2011). IBM SPSS for Introductory Statistics Use and Interpretation. New York, NY: Taylor \& Francis Group.

Nicholas, M.C. (2016). A Hopeful Pedagogy to Critical Thinking. International Journal for the Scholarship of Teaching and Learning, 10(2), 1-10.

Nicholas, M. C., \& Chalmer, E. L. (2013). Faculty Approaches to Assessing Critical thinking in the Humanities and Natural Sciences - A Grounded Theory Study (Doctoral Dissertation) University of Cincinnati.

Noe, R. (1999). Employee training and development. Boston, MA: McGraw-Hill Irwin.

Perkins C. \& Murphy, E. (2006). Identifying and Measuring Individual Engagement in Critical Thinking in Online Discussion: An Exploratory Case Study. Educational Technology \& Society, 9(1), 298-307.

Paul, R.W. \& Edler, L. (1997). California teacher preparation for instruction in critical thinking: Research findings and policy recommendations. Sacramento, CA: Commission on Teacher Credentialing.

Paul, R. \& Edler, L. (2005). Critical Thinking: Tools for taking charge of your professional and personal life. Upper Saddle River, NJ: Prentice-Hall.

Shim, W. \& Walczak. K. (2012). The Impact of Faculty Teaching Practices on the Development of Students' Critical Thinking Skills. International Journal of Teaching and Learning in Higher Education, 24(1), 16-30.

Smith, J. W. \& Stitis, D. K. (2013). Using Action Learning and Critical Thinking Tools to Make Changes in Higher Education. Contemporary Issues in Education Research, 6(1), 73-84.

Stein, B. \& Haynes, A. (2011). Engaging Faculty in the Assessment and Improvement of Students. Critical Thinking Using the CAT, 13(2), 44-49.

The Foundation for Critical Thinking. (2017). Critical Thinking Grid. Retrieved from https://www.criticalthinking.org/pages/critical-thinking-testing-and-assessment/594.

Timpson, W. (2002). Teaching and Learning Peace. Madison. WI: Atwood Publishing.

Tseng, C. (2006). Portraits of three teachers': Factors that influence transfer of learning. (Doctoral Dissertation) UMI No. 3252321.

Saudi Vision 2030. Retrieved from https://vision2030.gov.sa/en

Zhang, Q. \& Zhang, J. (2013). Instructors' Positive Emotions: Effects on Student Engagement and Critical Thinking in U.S. and Chinese Classrooms. Communication Education, 62(4), 395-411. 